\title{
FILMES FINOS DE CROMO NEGRO OBTIDOS POR ELETRODEPOSIÇÃO*
}

Gabriela Moreira Lana ${ }^{1}$ Rogério Antônio Xavier Nunes²

\section{Resumo}

A radiação solar apresenta uma enorme variedade de aplicações de engenharia, dentre elas, a conversão em energia térmica em concentradores solares. Os tubos absorvedores dos concentradores solares podem ser recobertos por cromo negro, com o objetivo de otimizar a absorção energética e a durabilidade. Esse trabalho é parte de um estudo complexo sobre esse tipo de recobrimento. Foram desenvolvidos filmes de cromo negro por eletrodeposição sobre aço inoxidável AISI 304 e tratados termicamente a $600^{\circ} \mathrm{C}$ por 2 horas. Os filmes foram caracterizados antes e depois do tratamento térmico, utilizando-se microscopia eletrônica de varredura (MEV), espectroscopia de energia dispersiva (EDS) e difração de raios X a baixo ângulo de incidência (GAXRD). Além do cromo, observou-se deposição de cobalto e elementos residuais do banho eletrolítico. $O$ estudo da estrutura cristalina mostrou formação de óxidos após tratamento térmico. Microestruturalmente, foram observados filmes com estrutura lamelar ou nodular. O estudo permitiu sugerir modificações do banho eletrolítico, do substrato e métodos adicionais de caracterização.

Palavras-chave: Cromo negro; Deposição eletrolítica; Filmes finos; Difração de raios $X$ a baixo ângulo de incidência.

\section{BLACK CHROME THIN FILMS OBTAINED BY ELECTROPLATING}

\begin{abstract}
Solar radiation may be used in a wide range of engineering applications, including the conversion into thermal energy in solar power plants. The absorber tubes of solar concentrators can be covered by black chrome, in order to optimize the energetic absorption and durability. This work is part of a complex study about this kind of coating. There were developed thin films of black chrome in 304 stainless steel samples, and annealed at $600^{\circ} \mathrm{C}$ for 2 hours. The samples were characterized before and after heat treatment using Scanning electron microscope (SEM), Energy dispersive spectrometer (EDS) and glancing angle x-ray diffraction (GAXRD). In addition to chromium, it was observed the deposition of cobalt and residual elements of the electrolytic bath. The study of crystal structure showed the formation of oxide after the heat treatment. Micro-structurally, there were observed films with lamellar or nodular structure. This study allowed the suggestion of changes in the bath composition, substrate and additional characterization methods.

Keywords: Black chrome; Electroplating; Thin films; Glancing angle x-ray diffraction

1 Engenheira de materiais, Departamento de Engenharia de Materiais, CEFET-MG, Belo Horizonte, MG Brasil.

2 Dr., Professor do Departamento de Engenharia mecânica, CEFET-MG, Belo Horizonte, MG Brasil
\end{abstract}




\section{INTRODUÇÃO}

O Brasil apresenta grande potencial para a construção de usinas solares, devido à sua posição geográfica favorável. Essa alternativa energética é livre de emissões, sendo uma tecnologia de grande interesse ambiental. Industrialmente, são utilizados hoje sistemas híbridos de captação de energia solar, devido à baixa eficiência. Filmes negros de cromo e níquel são amplamente utilizados em tubos absorvedores de concentradores solares devido às boas propriedades ópticas, condutividade e resistência ao desgaste [1]. O objetivo do trabalho é o desenvolvimento e caracterização de superfícies de cromo negro obtidas por eletrodeposição para aplicação em concentradores solares, contribuindo assim para a busca de eficiência associada a custo, favorecendo assim, interesses ambientais e industriais.

\subsection{Superfícies seletivas}

O revestimento dos tubos absorvedores é a peça chave dos concentradores solares. Os tubos devem apresentar baixas perdas térmicas e boa absortividade da energia solar. As superfícies que apresentam essas propriedades são chamadas "opticamente seletivas". Dos tipos de superfícies seletivas existentes [2], a superfície de cromo negro obtida por deposição eletrolítica é do tipo compósito metal-dielétrico, que apresenta elevada absortividade na região solar se depositada em uma superfície metálica refletiva. Esse revestimento é um cermet, ou seja, consiste em pequenas partículas cerâmicas dispersas em uma matriz metálica. Sua boa absortividade é explicada pelas transições entre as bandas do metal e pela ressonância entre as partículas [2]. A seletividade pode ser otimizada pela constituição química, espessura, cristalinidade, tamanho de partículas, morfologia e orientação.

\subsection{Deposição eletrolítica}

A deposição eletrolítica é um método muito utilizado para obtenção de revestimentos metálicos, que permite o controle de parâmetros importantes como composição química, composição de fases, microestrutura e espessura. O processo consiste basicamente na troca de elétrons entre duas semi-reações de oxirredução, através de dois eletrodos e o eletrólito. O catodo é a amostra a ser revestida, submetida a uma corrente elétrica que provoca a migração de partículas eletricamente carregadas presentes no banho químico. O outro eletrodo, o anodo, completa o circuito responsável pela corrente elétrica. O eletrólito, ou banho químico, deve conter sais iônicos do metal a ser depositado.

\subsection{Tratamento térmico}

Processos de degradação de revestimentos de absorvedores solares estão relacionados às temperaturas elevadas, umidade, condensação de água e poluentes. Existem estudos que submetem revestimentos de aplicação solar a tratamentos térmicos com o objetivo de simular o ambiente de aplicação [3]. No caso do cromo negro, o tratamento térmico tem como objetivos adicionais a dessorção de água e formação de óxidos para geração do cermet. 


\subsection{Métodos de caracterização}

\subsubsection{Microscopia eletrônica de varredura e espectroscopia de energia dispersiva}

O Microscópio eletrônico de varredura (MEV) é uma ferramenta capaz de gerar imagens topográficas de alta ampliação e resolução. Utiliza a energia transmitida pela interação de um feixe de elétrons com a amostra, promovendo uma varredura da superfície. Acoplado ao equipamento, existe um acessório de análise química, o EDS (espectrômetro de energia dispersiva), que utiliza o próprio feixe do microscópio para fornecer dados semi-quantitativos de composição química do material.

\subsubsection{Difração de raios $X$ a baixo ângulo de incidência}

A técnica de difração de raios $X$ baseia-se na presença de uma estrutura cristalina no material para determinar espectros característicos a cada fase presente. $O$ ensaio consiste na emissão de raios $X$ sobre a amostra, variando-se o ângulo de incidência e medindo-se a reflexão de acordo com a lei de Bragg. Cada interferência construtiva identificada pelo detector representa uma orientação cristalográfica, e cada conjunto de ângulos detectados (picos no difratograma) representa uma fase do material. A difração de raios $X$ a baixo ângulo de incidência consiste na incidência rasante do feixe de raios $X$, controlando a penetração de modo a minimizar ou reduzir a influência do substrato em estudos de filmes finos [4].

\section{MATERIAIS E MÉTODOS}

\subsection{Preparação de amostras}

As amostras polidas de aço inoxidável AISI 304 foram limpas com aguarrás e posteriormente com detergente. Parte delas foi então jateada com areia, e limpas em banho ultrassônico com água deionizada.

\subsection{Eletrodeposição}

Diferente de outros metais usados para deposição, a solução aquosa para deposição de cromo não pode conter apenas os íons do metal. Para possibilitar a deposição, a solução deve conter radicais ácidos, que agem como catalisadores no caso do cromo hexavalente, ou como complexantes no caso do cromo trivalente. Diante do caráter tóxico e cancerígeno do cromo hexavalente, a reação estudada foi feita a partir do cromo trivalente.

O banho químico e as condições de eletrodeposição utilizados são apresentadas na tabela 1. 
Tabela 1. Composição de banho e condições de operação de deposição de cromo

\begin{tabular}{l|l}
\hline Constituintes do banho & Quantidade (g/l) \\
\hline $\mathrm{CrCl}_{3} 6 \mathrm{H}_{2} \mathrm{O}$ & 266 \\
\hline $\mathrm{CoCl}_{2} .6 \mathrm{H}_{2} \mathrm{O}$ & 15 \\
\hline $\mathrm{H}_{2} \mathrm{SiF}_{6}$ & $8-12$ \\
\hline $\mathrm{NaH}_{2} \mathrm{PO}_{4}$ & 4 \\
\hline $\mathrm{NaF}$ & 21 \\
\hline Condições de operação & \multicolumn{2}{|l}{} \\
\hline Temperatura $\left({ }^{\circ} \mathrm{C}\right)$ & Temperatura ambiente $\left(25^{\circ} \mathrm{C}\right)$ \\
\hline
\end{tabular}

Fonte - Takadoum et al.(2010). Adaptação

$\mathrm{Na}$ composição escolhida, o ácido hexafluorossilícico, $\mathrm{H}_{2} \mathrm{SiF}_{6}$, é usado como agente oxidante. É necessário no mínimo $8 \mathrm{~g} / \mathrm{L}$ do reagente para que o revestimento seja formado [5]. Os cloretos e sulfatos são comumente usados para aumentar a condutividade da solução, também de grande importância no processo [6]. Foram feitos testes variando-se corrente e tempo de deposição.

\subsection{Tratamento térmico}

O tratamento térmico foi feito em duas etapas com duas das 6 amostras obtidas da eletrodeposição. A primeira etapa foi tratamento a $200^{\circ} \mathrm{C}$ por 2 horas e resfriamento lento dentro do forno. A segunda etapa foi um tratamento a $600^{\circ} \mathrm{C}$ por 2 horas e resfriamento lento. As demais amostras passaram por uma única fase de tratamento, sendo de 2 horas a $600^{\circ} \mathrm{C}$ e resfriamento lento.

\subsection{Caracterização}

O MEV utilizado foi um SSX-500 da marca Shimadzu, onde foram feitas imagens por elétrons secundários com tensão de aceleração do feixe de $15 \mathrm{kV}$.

A difração de raios $X$ foi feita no equipamento XRD-7000 da marca Shimadzu, onde foi utilizado o acessório de baixo ângulo de incidência. A análise foi feita com varredura contínua de $25^{\circ}$ a $100^{\circ}$, passo de $2^{\circ}$ min e ângulo de incidência variável. $O$ tubo de raios $X$ utilizado é de cobre, de tensão $40 \mathrm{kV}$ e corrente $30 \mathrm{~mA}$. Os difratogramas foram analisados no software X-Powder Ver. 2004.04.70, com banco de dados PDF2.DAT 2003 disponibilizado pelo International Center for Diffraction Data (ICDD).

\section{RESULTADOS E DISCUSSÃO}

\subsection{Substrato}

O primeiro passo foi a análise do substrato, quanto à composição química por espectroscopia e estrutura cristalina antes e depois de um tratamento térmico por difração de raios $X$. Os resultados são apresentados na tabela 2 e figura 1. 
Tabela 2: Análise química do substrato

\begin{tabular}{|c|c|c|c|c|c|}
\hline Element & AT\% & K-Value & A & & \\
\hline$c$ & 12.424 & 0.01276 & 0.90261 & 3.56690 & 1.00000 \\
\hline $\mathrm{Si}$ & 1.212 & 0.00615 & 0.91958 & 1.66051 & 0.99715 \\
\hline $\mathrm{Cr}$ & 16.847 & 0.27509 & 1.01333 & 1.00601 & 0.85982 \\
\hline Mn & 1.974 & 0.02995 & 1.03148 & 1.00227 & 0.96404 \\
\hline $\mathrm{Fe}$ & 61.136 & 0.91533 & 1.01226 & 1.01750 & 0.99684 \\
\hline $\mathrm{Ni}$ & 6.407 & 0.09633 & 0.99764 & 1.05961 & 1.01665 \\
\hline
\end{tabular}

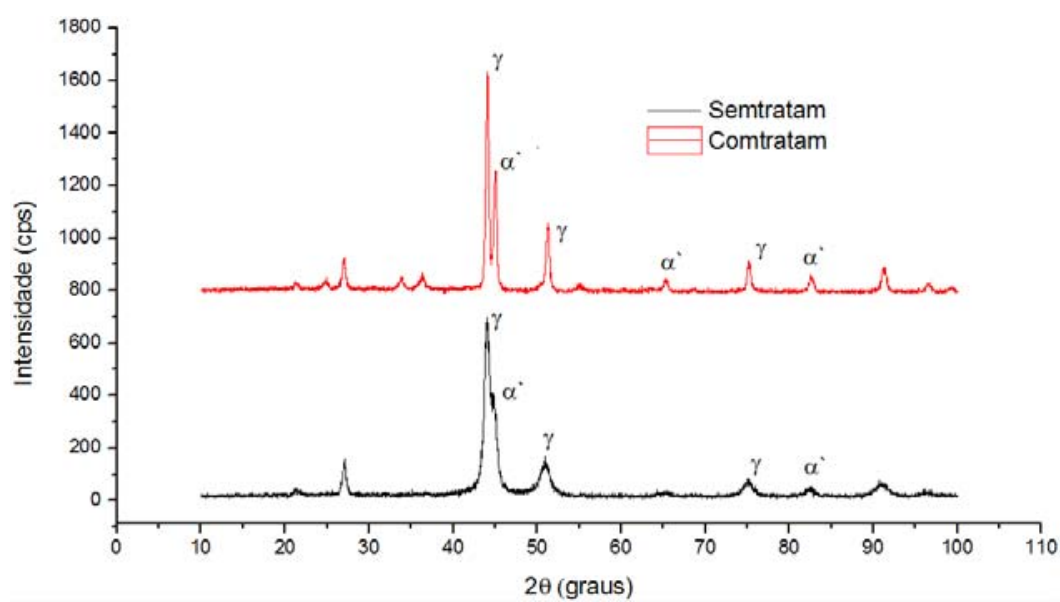

Figura 1: Difração de raios $X$ do substrato antes e depois de tratamento térmico

O difratograma do substrato sem filme, em conjunto com a análise química, indica um aço inoxidável AISI 304. A presença de grande quantidade de martensita pode ser explicada por se tratar de um material em chapas, ou seja, em sua forma laminada. O processo de laminação a frio de aços austeníticos pode levar à formação de martensita durante a deformação plástica. Um dos picos de martensita coincide com o pico principal de cromo metálico $\left(44^{\circ}\right)$, o que indica a primeira dificuldade da utilização desse tipo de substrato, visto que a análise será feita, a princípio, de forma semi-quantitativa.

\subsection{Eletrodeposição}

As amostras selecionadas após a eletrodeposição são apresentadas na tabela 3 . Sua seleção foi baseada na aparência uniforme e escura do filme depositado, assim como na boa adesão observada visualmente. Na tabela 3 são apresentados, além dos principais parâmetros, corrente e tempo, se o eletrodo foi usado pela primeira vez na deposição em questão e o tempo entre a reação e a deposição.

Tabela 3 - Amostras selecionadas para caracterização e parâmetros de processo

\begin{tabular}{l|l|l|l|l|l|l|l}
\hline Amostra & Substrato & $\begin{array}{l}\text { Preparação } \\
\text { de amostra }\end{array}$ & Corrente & Tensão & $\begin{array}{l}\text { Tempo de } \\
\text { deposição }\end{array}$ & Eletrodo & $\begin{array}{l}\text { Tempo } \\
\text { de } \\
\text { reação }\end{array}$ \\
\hline 1 & Aço 304 & Nenhuma & $5 \mathrm{~A}$ & $19,5 \mathrm{~V}$ & $90 \mathrm{~s}$ & Novo & 1 semana \\
\hline 5 & Aço 304 & Polido & $5 \mathrm{~A}$ & $18,4 \mathrm{~V}$ & $90 \mathrm{~s}$ & Novo & 5 horas \\
\hline 6 & Aço 304 & Jateado & $5 \mathrm{~A}$ & $14,7 \mathrm{~V}$ & $90 \mathrm{~s}$ & Usado & 5 horas \\
\hline 21 & Aço 304 & Nenhuma & $4 \mathrm{~A}$ & $12,9 \mathrm{~V}$ & $90 \mathrm{~s}$ & Novo & 5 horas \\
\hline 22 & Aço 304 & Nenhuma & $5 \mathrm{~A}$ & $10,7 \mathrm{~V}$ & $90 \mathrm{~s}$ & Usado & 5 horas \\
\hline 23 & Aço 304 & Jateado & $5 \mathrm{~A}$ & $12,4 \mathrm{~V}$ & $90 \mathrm{~s}$ & Usado & 5 horas \\
\hline
\end{tabular}


Observa-se que as amostras selecionadas foram depositadas com corrente elevada. A literatura aborda correntes inferiores a $3 \mathrm{~A}$, porém um estudo detalhado da corrente só pode ser feito mantendo-se os demais parâmetros fixos. Além disso, foi observado que o eletrodo não afetou as deposições, sendo que foram obtidas boas amostras com eletrodo novo ou usado. Isso pode ser explicado pelo fato de que o eletrodo sofre oxidação e perda de massa durante o processo, o que não afeta a deposição seguinte.

O tratamento térmico em duas etapas foi feito nas amostras 1 e 5 , enquanto as demais amostras passaram por tratamento térmico em única etapa.

\subsection{Microestrutura e composição química}

Da análise química dos filmes depositados, observou-se grande quantidade de cromo em todas amostras, porém foram constatados também elementos como cobalto em grande quantidade, e oxigênio, carbono, cloro, sódio e ferro em menores quantidades. $\mathrm{O}$ cromo era um elemento esperado em grande quantidade, porém o cobalto era esperado em pequena quantidade, sendo elemento residual do banho eletrolítico. Sua deposição pode ser explicada por uma elevada afinidade ou pela elevada concentração no banho químico. Dos outros elementos encontrados, o oxigênio é atribuído ao início da formação de óxidos nos filmes e o carbono é residual do eletrodo de grafita utilizado. O ferro encontrado na análise do filme é referente ao substrato, visto que as análises químicas foram feitas em quadros, e não pontualmente, e os filmes apresentam porosidade que evidencia o substrato. Os demais elementos encontrados são residuais do banho eletrolítico.

Após o tratamento térmico, observou-se aumento do teor de oxigênio e ferro. Os teores de cromo e cobalto foram mantidos altos e os demais elementos não foram identificados ou foram identificados em menor quantidade. O aumento do oxigênio após tratamento térmico era esperado devido à formação de óxidos. $O$ teor de ferro na análise apresentou-se maior devido ao aumento esperado de porosidades e microfissuras, revelando ainda mais o substrato. Os demais elementos podem ter sido volatilizados, dessorvidos ou presentes em pequenas quantidades não detectáveis.

Na figura 2, tem-se imagens de microscopia das amostras 1, 5, 6, 21, 22 e 23 antes do tratamento térmico, respectivamente, com aumento de 2400 vezes. 

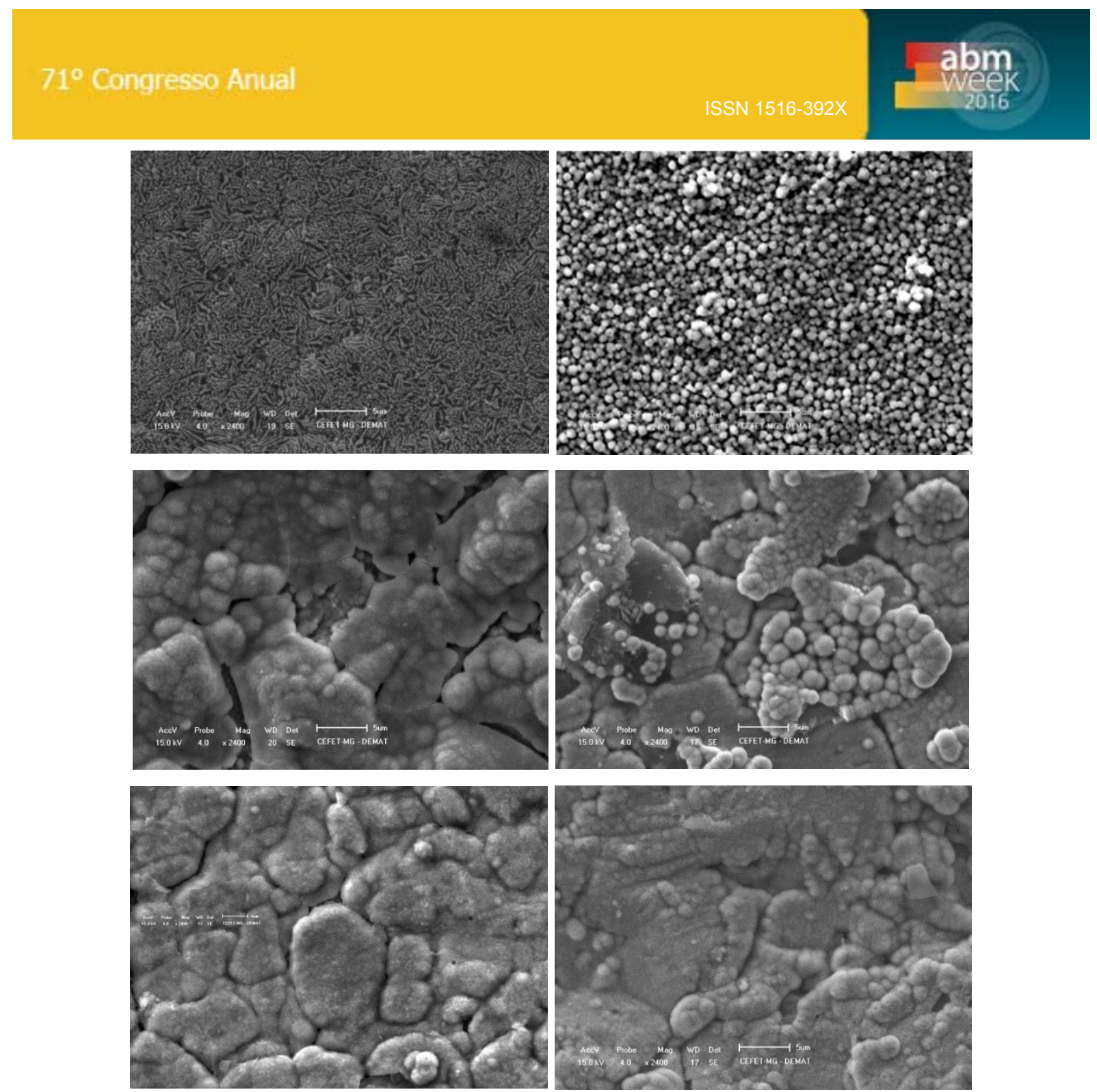

Figura 2 - Imagens de MEV das amostras 1 e 5 (topo), amostras 6 e 21 (centro), amostras 22 e 23 (inferior). Antes do tratamento térmico.

$\mathrm{Na}$ amostra 1, foi observada a formação de uma estrutura porosa dividida em conjuntos de lamelas com diferentes orientações. A amostra 5 apresentou morfologia também porosa, porém nodular. As demais amostras apresentaram morfologias semelhantes, divididas em placas, apresentando microfissuras e alguns nódulos.

Após o tratamento térmico, observou-se que as duas amostras que passaram por duas fases (amostras 1 e 5 ) apresentaram fragmentação e desprendimento visível do filme. O fato é indicativo da instabilidade do filme formado, que pode ser explicado de forma diferente para cada amostra. A amostra 1 foi depositada por um banho que passou uma semana sofrendo reação, o que indica que o tempo excessivo de reação da mistura química pode não ser adeuqada. Quanto à amostra 5 , o desprendimento do filme pode ser atribuído à preparação da superfície do substrato, ou seja, a amostra foi apenas polida, logo, a baixa rugosidade pode afetar a adesão e estabilidade do filme.

Na figura 3, são mostradas imagens de microscopia das amostras após o tratamento térmico das amostras 6, 21, 22 e 23.Observa-se aumento das microfissuras, evidenciando o substrato. 

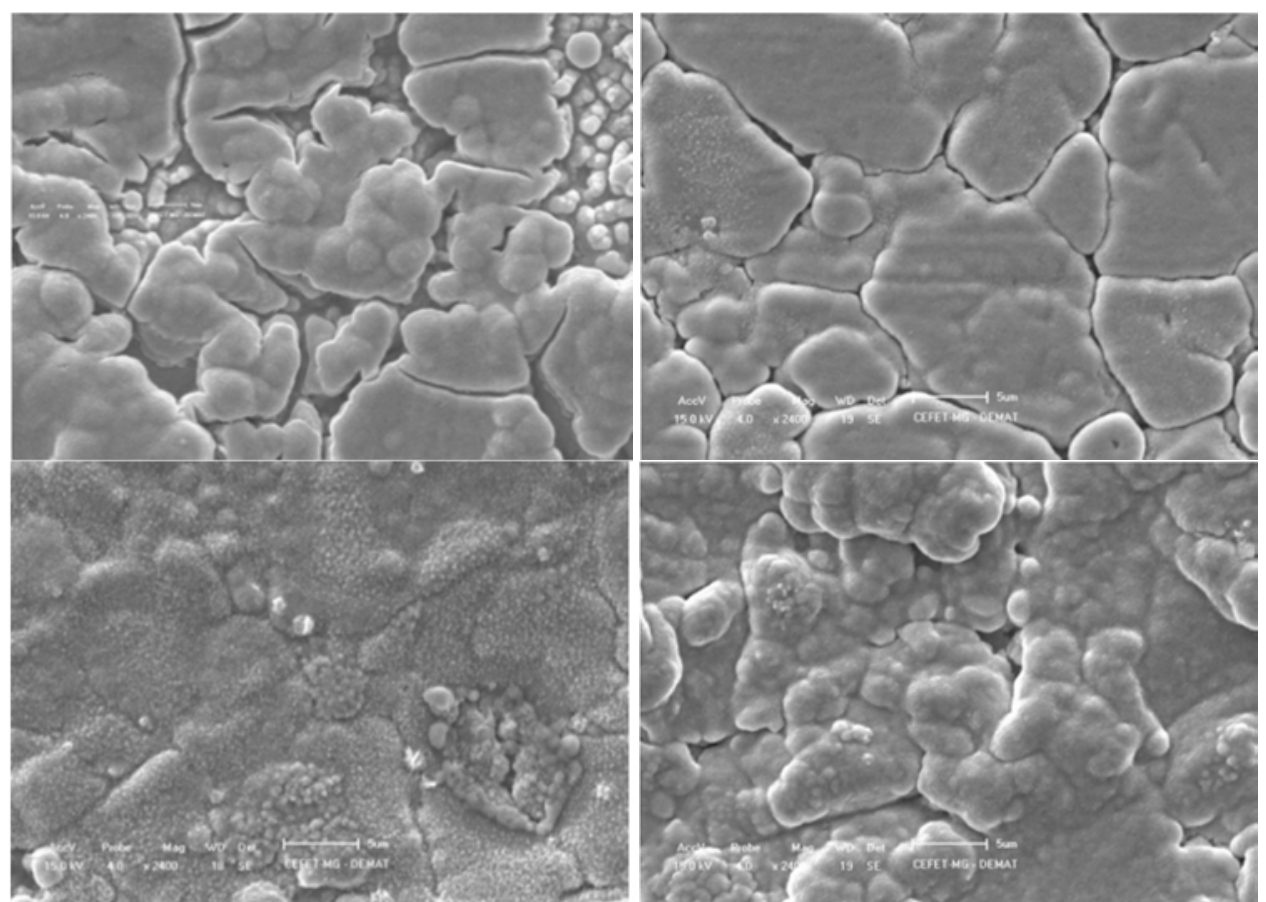

Figura 3 - Imagens de MEV das amostras 1 (a), amostra 5 (b), amostra 6 (c), amostra 21 (d), amostra 22 (e) e amostra 23 (f). Após tratamento térmico.

\subsection{Estrutura cristalina}

A análise da estrutura cristalina das amostras antes do tratamento térmico mostrou que a amostra 1 apresenta estrutura bem diferente das demais, como observa-se nas figuras 4 e 5 . A presença de sódio foi evidenciada apenas na análise da primeira amostra. Nas demais amostras, foi observada presença de cromo e cobalto metálico. O cromo foi identificado segundo o card 060694,e corroborado por Khojier et al.[7]

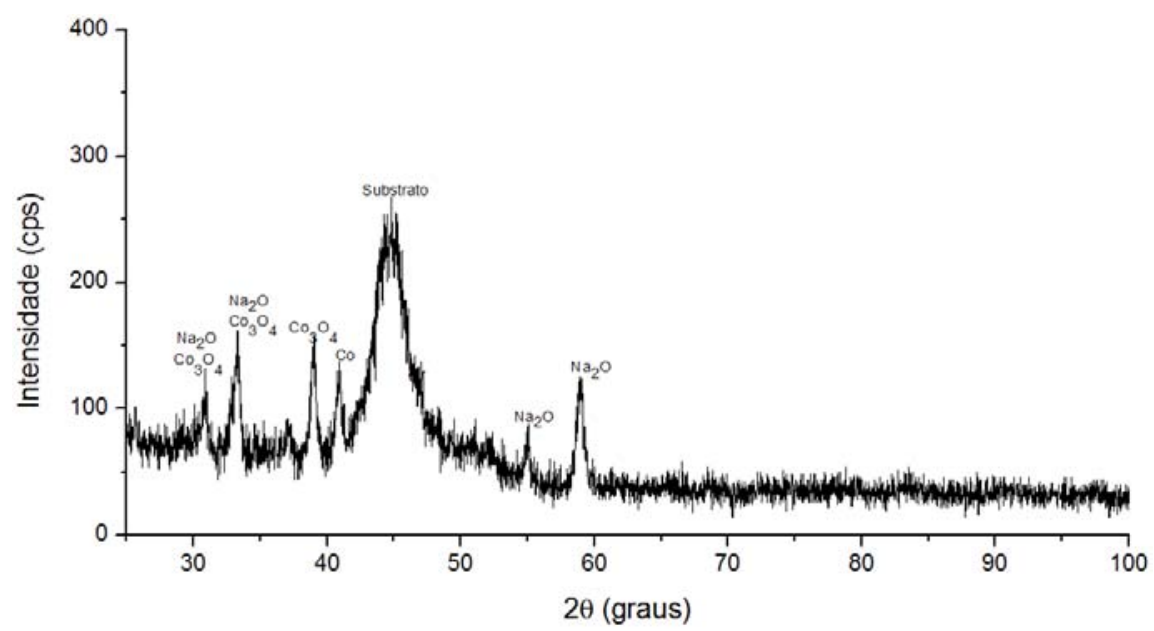

Figura 4: Difração de raios $X$ a baixo ângulo da amostra 1 antes do tratamento térmico 


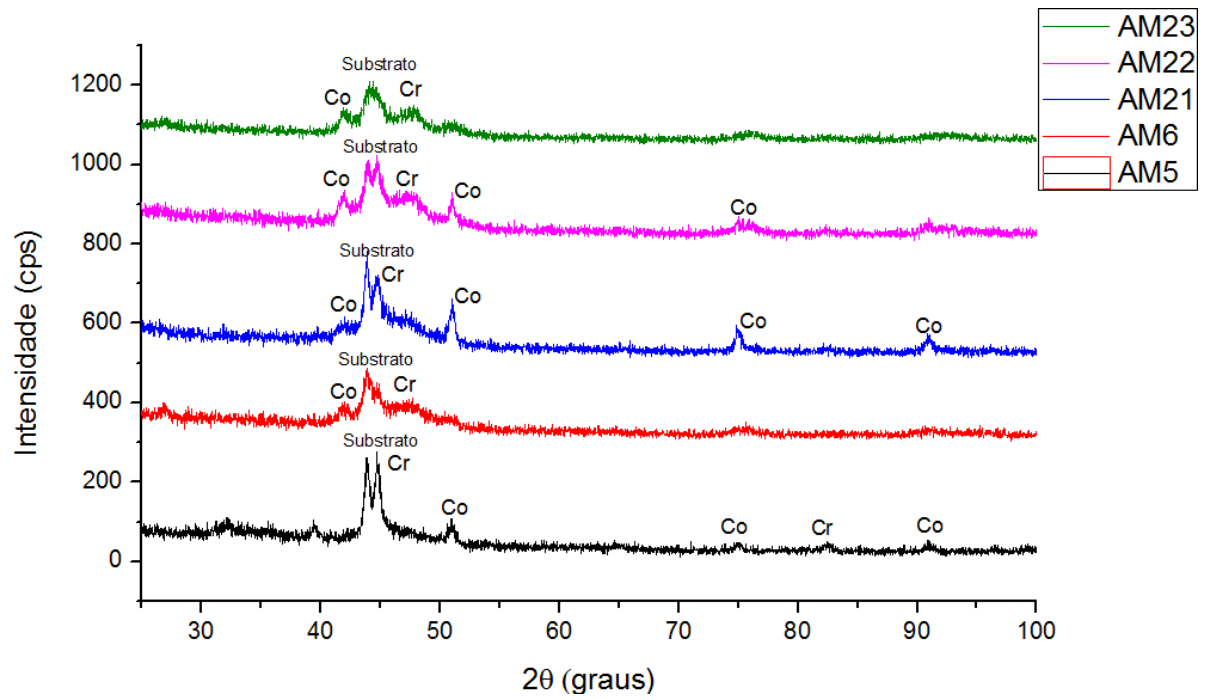

Figura 5: Difração de raios $X$ a baixo ângulo das amostras 5, 6, 21, 22 e 23 antes do tratamento térmico.

Após o tratamento térmico, foi feita a análise das amostras 6, 21, 22 e 23 apresentada na figura 6 . Pelos difratogramas, comprova-se que o aumento do teor de oxigênio nas amostras é atribuído à formação de óxidos de cromo e cobalto.

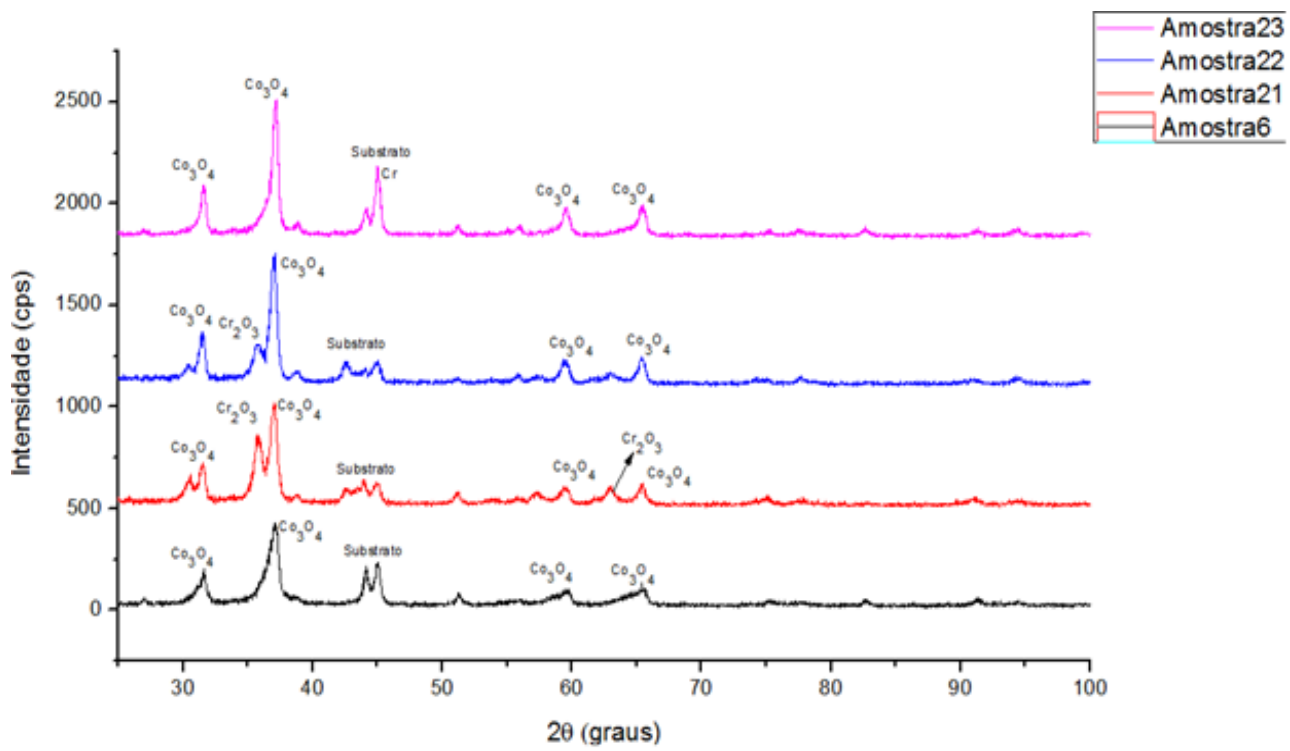

Figura 6: Difratograma das amostras 6, 21, 22 e 23 após tratamento térmico

As análises foram feitas variando-se o ângulo de incidência, e observa-se uma dessas análises na figura 7. Observa-se que, para menores valores de ângulo de incidência, não há influência do substrato, porém a intensidade de sinal detectada é muito pequena. 


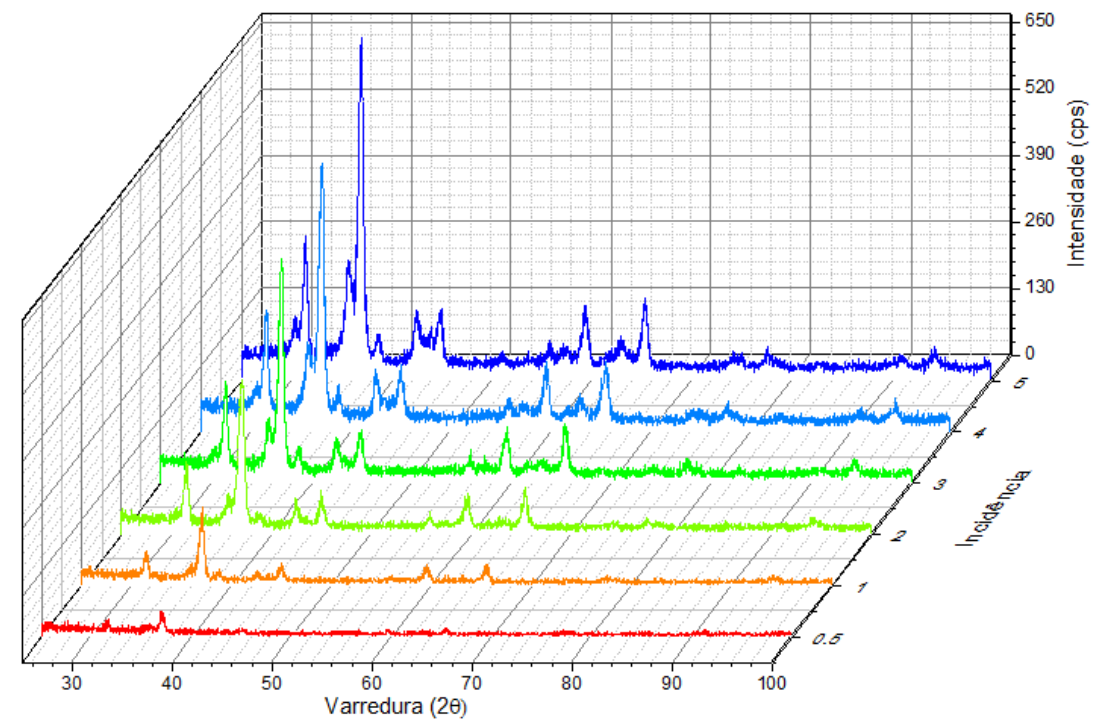

Figura 7: Difratograma de baixo ângulo da amostra 23 pós tratamento térmico variando-se o ângulo de incidência.

\section{CONCLUSÃO}

Os filmes obtidos apresentaram porosidade, como era esperado de estudos anteriores. A diferença entre estrutura nodular ou lamelar não seguiu um padrão associado aos parâmetros utilizados, o que requer um estudo mais detalhado. A presença de microtrincas também foi observada em todas as amostras, e ampliada após tratamento térmico. Essa característica pode afetar propriedades importantes do filme como resistência à abrasão e propriedades ópticas.

Sobre o banho químico utilizado, conclui-se que é um fator que requer grande controle. Sugere-se a redução da concentração do cloreto de cobalto e aumento da concentração de ácido hexafluorossilícico.

O tratamento térmico foi uma etapa de grande importância, e atingiu os objetivos esperados de revelar a resistência do filme depositado e formar óxidos. A caracterização foi feita com técnicas adequadas e satisfatórias, porém o cermet formado deve ser estudado também quanto às propriedades ópticas, parâmetro de grande importância no caso de recobrimento de coletores solares.

Um próximo passo para o desenvolvimento desse tipo de recobrimento é o estudo em substrato em formato cilíndrico, aproximando-se da real aplicação.

\section{Agradecimentos}

Agradecimentos à FAPEMIG pelo financiamento e incentivo à pesquisa.

\section{REFERÊNCIAS}

1 TAKADOUM, J.; Black coatings: a review. The European Physical Journal Applied Physics. v1. 15p. November 2011

2 KENNEDY, C. E. Review of mid- to high- temperature solar selective absorber materials. National Renewable Energy Laboratory, Bechtel, USA. Jun. 2002.

3 KOTILAINEN, M., MIZOHATA, K., HONKANEN, M., VUORISTO, P. Influence of microstructure on temperature-induced ageing mechanisms of different solar absorber 
coatings. Solar energy materials and solar cells. Tampere University of Technology, Tampere, Finlândia. 2013

4 BOUROUSHIAN, M., KOSANOVIC, T. Characterization of thin films by low incidence $x-$ ray diffraction. Scientific Research. National technical University of Athens, Atenas, Grécia. Dezembro 2012.

5 HAMID, Z. A. Electrodeposition of black chromium from enviromentally electrolyte based on trivalente chromium salt. Surface and coatings technology. Central metallurgical research and development institute. Cairo, Egito. Maio 2009.

6 MANDICH, N, V., SNYDER, D. L. Electrodeposition of chromium. In. SCHLESINGER, M. Modern Electroplating, $5^{\text {th }}$ edition. Ontario, Canada. Wiley, 2010.p 205 - 248

7 KHOJIER, K., SAVALONI, H., ASHKABUSI, Z., DEHNAVI, N. Z. Structural, mechanical and tribological characterization of chromium oxide thin films prepared by postannealing of $\mathrm{Cr}$ thin films. Applied Surface Science. Islamic Azad University, Chalous, Irã. 2013

8 GIOVANARDI, R., ORLANDO, G. Chromium electrodeposition from $\mathrm{Cr}$ (III) aqueous solutions. Surface and Coatings Technology. Fevereiro 2011.

9 KHAMLICH, S.; NEMRAOUI, O.; MONGWAKETSI, N.; MCCRINDLE, R.; CINGO, N.; MAAZA, M. Black Cr/a- $\mathrm{Cr}_{2} \mathrm{O}_{3}$ nanoparticles based solar absorbers. Elsevier. 4p. 2010

10 WASEDA, Y., MATSUBARA, E., SHINODA, K. X-ray diffraction crystallography. Springer. Sendai, Japan, 2011 